\title{
Exploration on the Innovation Education and Cooperative Cultivation of Printing Engineering Rated as the First-class Major in Beijing
}

\author{
Yong-Gang YANG ${ }^{1, a}$, Jia-Wei ZHAO ${ }^{1, b}$, Rui-Na WANG ${ }^{1, c}, K^{2} Y_{A N G}^{1, d^{*}}$ and \\ Qiao-Zhuo GAO ${ }^{2, e}$ \\ ${ }^{1}$ Beijing Institute of Graphic Communication, Beijing, China \\ ${ }^{2}$ The Emerald City Branch of Beijing Primary School, Beijing, China \\ a2207063089@qq.com, ${ }^{\text {b22816747188@qq.com, }{ }^{\text {C5 } 545456136 @ q q . c o m, ~}{ }^{d} 24632843 @ q q . c o m,}$ \\ 'gaoqiaozhuo@sina.com \\ *Corresponding Author
}

Keywords: First Class Major, Printing Engineering, Innovation Education, Cooperative Cultivation, Engineering Practice

Abstract. Printing engineering is the leading major of Beijing Institute of Graphic Communication with a long history and a deep accumulation. The mechanism of innovative education and cooperative education will be explored on an opportunity of the construction pilot of the First-class Major in Beijing. This paper firstly introduced the system of "Four in One" innovation personnel training and the innovation education achievements, and then expounds the domestic and foreign institutions and professional cooperative training mechanism and resources sharing mechanism, paving the way for the strengthening of first-class major construction quality.

\section{Introduction}

The printing engineering of our school has paid attention to the innovative and entrepreneurship education, and taken it as the guiding ideology that the innovation education should embody the major characteristics, the innovation management organization should focused on the frontiers of society, and the innovation activities should be combined with the industry needs. We explored a "theory for innovation, practice for entrepreneurial" mode according to the innovation and entrepreneurship education integrated into the talent training system.

\section{The Integration into the Talent Training System and Curriculum System with Innovation and Entrepreneurship Education}

Strengthening top-level design, and establishing the "four in one" innovative talent training system for printing engineering. In Beijing Institute of Graphic Communication, the undergraduate innovation park was built, the entrepreneurship salons were organized, the innovation and entrepreneurship competitions were carried out, the top-level design for innovation education was strengthened, and the innovation management institutions were perfected. The innovation and entrepreneurship elements have been added to the training plan revision, the teacher's faculty construction and the curriculum setting on the guide of the school innovation activities policy for the printing engineering major. In order to further promote and implement the innovative and entrepreneurship education, we have built a number of practice teaching platforms for training students' practical ability, such as 22 off-campus practice teaching bases (including one municipal base), printing engineering comprehensive training center (Beijing municipal level), printing and packaging innovation education base (Beijing municipal level) and printing electronic engineering technology research center (Beijing municipal level), and then a complete "four in one" innovative personnel training system was perfected, which laid a solid foundation for enhancing students' practical innovation consciousness and abilities.

Implementing the "123" project and strengthening the process guidance to cultivate excellent innovation education achievements. Printing engineering major promote vigorously the 
"123" project that a teacher must guide not less than three students to carry out the innovative ability training on the base of at least two innovation and entrepreneurship project, and follow the whole process of selecting the subject, designing the scheme, preparing material and demonstrating the innovative results. In the major training program, some new courses, for example "3D printing technology and application" and "printing culture communication", were set up, which can take that the innovative results come from certain curriculums, and serve for them. On the based of the curriculum systems including innovation elements, fostered by the school innovation park, students' abilities of innovation and entrepreneurship have been raised significantly, and the creative themes have been outstood vividly, so it gained many fruitful achievements of innovation and entrepreneurship education. Among them, the students performed well in the sixth and eighth "Challenge Cup" Capital University Students' extracurricular academic science and technology works competition, and they won a number of awards as the second prize and the third one. Some excellent students' works as the "New Youth Dream and Drunk Red Mansion " noctilucent hollow book and the 3D solid landmark cartoon map, made by the 2014 grade students in the stage of the second school "Creative Printing" design plan contest, won the gold medal and bronze medal in the fifth session of the students' science and technology innovation and patent achievements promotion conferences.

\section{The Cooperative Training Mechanism of Printing Engineering and Domestic Institutions and the Mechanism of Co-construction and Sharing of Resources}

The printing engineering has pursued constantly the cooperation with domestic colleges, enterprises and local government to run schools jointly and set up a new talents cultivation mechanism. Meanwhile the specialty has initiated several ways to co-construction mode as it deeply cooperates with government technology apartment, association, science parks and enterprises and makes the most of political and social resource.

Focusing on professional communication and exploration, and initiating new mechanism between colleges and research institutions, local governments. In 2013, the specialty developed inter-regional talents cooperative cultivation with printing engineering in Hangzhou University of Electronic Science and Technology and Tianjin University of Science and Technology, and implemented exchange students training program. The specialty has become the pioneer of sharing high quality education in printing and packaging universities and colleges by exchanging students and transferring credits. In 2016, the school has built 'the Jingnan University Alliance' with the other two universities in Daxing District, and published 'the action plan of Jingnan University Alliance severs Daxing district' and promoted talents cultivation in several ways and deep cooperation in social service.

The specialty participated 'the talents cross training program' positively which Beijing normal universities and colleges first implemented since September in 2015, including graduation project and graduation thesis and the project and thesis adopt the dual-mentor system. Excellent students can get scientific research and innovation training in Chinese academy of science and it provides a new mode of cultivating student's scientific research and innovation ability. In the recent two years, the specialty has developed 11 kinds of cooperative programs with Institute of mechanics of the Chinese Academy of Sciences and remote sensing and nanometers that format Good cooperative training mechanism.

Creating Artron characteristic class and talents cultivation advantage platform and strengthening engineering practice education. 'Artron Class' is the joint education program of Beijing Institute of Graphic Design and Communication and Artron Art Group strategic cooperation. Since 2012 Artron Class has recruited students from printing engineering, packaging engineering and digital media technology to conduct job training and directed education. Meanwhile the scientific research training program of 'the talents cross training program' is the cooperation between school and Artron Art Group for strengthening student's practical ability and solving actual production problems.

'Bisheng excellent class' was set up after using printing engineering as the experimental project 
by ministry of education. Since starting in 2012, it has set up five turns and each turn has one class.

Besides, school constructed characteristic cooperation platform based on source sharing and student's innovation training with Leo Pap Group, Lukka Packaging and TPU Supplies. And it laid a solid foundation for cooperative training program of extending printing engineering and cultivating talents within country.

Carrying out the cooperation with industry management departments and establishing the resource platform. The State Administration of radio and television the green printing test laboratory of the publishing product quality supervision and detection centre was constructed by Beijing green printing and packaging industry technology research institute and General Administration of product quality inspection centre. The green printing test laboratory staged product quality supervision and standard making, technology consultation. And it developed cooperation in cultivating talents for service and quality supervision to promote the development of printing industry in digital and environmental directions. Right now the printing engineering students join in every research and testing program of the laboratory by dual innovation, course experiments and graduation project such as printing ink, fountain solution and VOC emission monitor of vehicle cleaning water.

The base of Beijing Institute of Graphic communication, the capital technical platform, is the service base of exploring experiments constructed by Beijing Institute of Graphic communication and Beijing Science community. Relying on capital innovation vouchers, foreign enterprises have access inside base and school and reach intention of cooperation. Universities and colleges finish the need dock of key laboratory and enterprises to reach the win-win situation.

Constructing some science research platforms with the associations and enterprises. Zhongguancun online open laboratory is constructed jointly by Beijing Institute of Graphic Communication and Zhongguancun Science and Technology Park. The school provided test force and source and the park provide policies and market assist that initiate the model of cooperation between Beijing colleges and universities and Park. The lab has advanced facilities used for testing and analyzing printing and packaging materials and property of information technology materials. Right now the laboratory provides high quality testing service for Tsinghua University, Beijing Institute of Technology, Harbin Institute of Technology and Founder Group.

China Ink Research Centre was constructed by Beijing Green Printing and Packaging Industrial Technology Research Institute and Ink branch of China Light Industry Association. Fortuna Imatek and BIGC united laboratory was constructed by Fortuna Imatek and Beijing Institute of Graphic Communication. Both of them provide test, research service and environmental ink standards to enterprises by utilizing the leading position and advanced testing facilities in ink innovation platform. Right now, printing engineering students through municipal and school-level research projects and graduation design participate in a variety of development and achievements of UV ink, water-based gravure ink, UV ink-jet ink, UV ink and waterless offset fluorescent ink-jet ink that has improved the students' level of innovation and entrepreneurship, and guarantee the quality of personnel training improved steadily.

\section{The International Joint Supervision and Resource Co-construction Mechanism of Printing Engineering Major}

To accommodate the tendency of education internationalization, the school branched out into the all-round, multi-level mechanism of international exchange and cooperation, such as exchanging visits of teachers and students for short-term, and joint supervision. In the practical exploration of international talent cultivation mode, persist with the cultivation conception of "High-quality internationalized talents with specialty characteristics", and stick at combining with connotation construction and extensional expansion. Integrate "Going global” with "Coming indoor", attach great importance to both teachers' international quality promotion and talent cultivation model innovation, aggregate essentials and resources about domestic and international printing education to build the international talent growth environment which is beneficial to conjoint cultivate talent.

Expanding horizons and exploring the new model of international talents cultivation. Perfect courses taught with bilingual and English gradually, expand the exchange program with foreign 
countries and regions positively, and explore the new model of international talent cultivation to build strong foundation for achieving "Going global” strategy well. In the construction of "One Belt and One Road (OBOR called for short)", BIGC accounts the positive fame accumulated by cultivating teachers and students of printing specialty for Asian countries over many years, masterminds positively the cultivation plan of international students and teachers' reserves for OBOR, and also builds international brands that obtained with highly praised from OBOR countries. The international joint cultivation model is beneficial to students to expand horizon. In addition, it enhanced the communication of academic and culture about OBOR by increasing numbers of international students, By joint cultivation, disseminating Chinese traditional culture to overseas enhances the level of course construction and broaden the international repute of printing engineering specialty.

Establishing the joint culture exchange system and sending outstanding students to study abroad. In 2013, BIGC instituted a range of projects, such as Measures for Singling Out Exit Scholarships, Regulations on the Management of Short-term Student Exchanges Abroad, Measures for the Management of Students Studying Abroad, International exchange learning and Joint Training of Beijing Institute of Graphic Communication (for Trial Implementation), and the regulation about catching and cultivating international students.

In 2012, BIGC signed the protocol with National Taiwan University of Arts. Select four professional students to exchange learning for one year, and state credits each other. In the same year, BIGC signed the 1+2+1 Chinese and American Talent Development Program with China Education Association Center for International Exchange, select same numbers of students and send them to American partner universities to study for a period of time, and they will gain two degree diplomas after graduation. One student from printing engineering specialty studied abroad in California State University in that year. Besides, BIGC signed cooperation agreement with American Ball State University, Rochester Institute of Technology, London University of the Arts, Stuttgart Media University, Japan Chiba University, Sweden Linkoping University, Moscow State University of Print and Art, India Guru Jambheshwar University of Science and Technology and other universities, for steadily promote international talent cultivation.

Taking full use of international cooperation resources and promoting the model and influence of specialty. In November, 2015, the "International Cooperation Base for Green Printing and Publishing Technology” jointly declared by BIGC and international cooperation units Linköping University in Sweden, Chiba University in Japan and the Swedish Institute of Paper, Printing and Packaging Technology, etc., was recognized by the Ministry of Science and Technology, which provides a excellent platform for international talent cultivation, science and technology cooperation, resources sharing and personnel quality improvement.

The Department of Printing Engineering and X-Rite established the X-Rite color laboratory and training center in the printing engineering laboratory. By using advanced color measuring equipment, color management, and evaluation methods of printing engineering specialty to calibrate prepress output device color and evaluation of color reproduction effect of printed image products, providing training bases and exchange platforms for color measurement and color management technologies for printing technicians in Asian countries. Using resources of the laboratory, the professional completed the establishment of the domestic ink color matching system database. On the one hand, it has improved students' scientific research capabilities, and at the same time, it has also served the industry very well and has expanded the professional radiation demonstration effect.

Solidified the foundation of cooperation and expanding cooperation resources and models. The professional and the IGT company in the Netherlands established a cooperative relationship, established the IGT printability laboratory, become IGT's equipment and technical training center with the most complete equipment and the longest history in Asia and even the world. On the one hand, the laboratory serves as an Asian user training platform for IGT Company. On the other hand, it becomes an important teaching and research platform for courses, such as printing principle and technology and printed materials in the core courses of printing specialty. Relying on the IGT Printing Suitability Laboratory, we completed the testing of printing suitability for paper and ink, and provided a good foundation for the development of international, national and industry standards and 
new technologies for paper, ink, and printing process control.

In addition, the specialty is going to start the mini-Printing Micro-curriculum Construction Project. Beginning with the Chinese Micro-curriculum and expand to English, German and Japanese curriculum, orderly construct the global sharing system of high quality resource for sharing printing education through multiple methods.

\section{Acknowledgement}

This work was financed by 2015 key projects of teaching reform research of Beijing Institute of Graphic Communication (Grant number: 22150116007/049).

\section{References}

[1] WANG Xiaoqian. Study on college students creative education and the entrepreneurial talents training mode [J], Modern Communication, 2017(10):1.

[2] LI Boni, LIU Tiantian, LIU Ze. Thinking and exploration on innovation and entrepreneurship education of universities [J], China Trainning, 2017(6):122.

[3] FU Xujian. The combination and path management of talent training and innovative education in applied undergraduate colleges [J], Journal of Jishou University (social sciences edition) , 2016(6): 168-171.

[4] CAI Zhiqi. Initial analysis on the diversification of cooperative education model in applied undergraduate colleges [J], Research in Teaching, 2014(7): 5-8.

[5] WU Yusheng. Research on the cooperative educating path of college and enterprise [J], Heilongjiang Educatin, 2014(6):74-76.

[6] JIN Xianglei, ZHAO Ji. Promoting the cooperation of universities and scientific research institutes to build a collaborative education platform for science and education [J], China University Teaching, 2013(5):21-22. 